\title{
The use of complementary and alternative medicine by patients with cancer: a cross- sectional survey in Saudi Arabia
}

\author{
Khadega A. Abuelgasim ${ }^{1,2^{*}}$, Yousef Alsharhan ${ }^{3}$, Tariq Alenzi ${ }^{3}$, Abdulaziz Alhazzani ${ }^{3}$, Yosra Z. Ali ${ }^{2}$ \\ and Abdul Rahman Jazieh ${ }^{1,2}$
}

\begin{abstract}
Background: A significant proportion of cancer patients use complementary and alternative medicine (CAM) along with conventional therapies (CT), whereas a smaller proportion delay or defer $\mathrm{CT}$ in favor of CAM. Previous studies exploring CAM use among cancer patients in the Middle East region have shown discrepant results. This study investigates the prevalence and pattern of CAM use by Saudi cancer patients. It also discusses the possible benefits and harm related to CAM use by cancer patients, and it explores the beliefs patients hold and their transparency with health care providers regarding their CAM use.

Methods: A cross-sectional study was conducted in oncology wards and outpatient clinics by using face-to-face interviews with the participants.

Results: A total of 156 patients with a median age of 50 years (18-84) participated in the study. The prevalence of CAM use was 69.9\%; the most prominent types of CAM were those of a religious nature, such as supplication (95.4\%), Quran recitation (88.1\%), consuming Zamzam water (84.4\%), and water upon which the Quran has been read (63.3\%). Drinking camel milk was reported by $24.1 \%$ of CAM users, whereas camel urine was consumed by $15.7 \%$. A variety of reasons were given for CAM use: $75 \%$ reported that they were using CAM to treat cancer, enhance mood (18.3\%) ,control pain (11.9\%), enhance the immune system (11\%),increase physical fitness (6.4\%), and improve appetite (4.6\%). Thirty percent of CAM users had discussed the issue with their doctors; only 7.7\% had done so with their nurses.

Conclusions: The use of CAM, including camel products, is highly prevalent among cancer patients in the Middle East, but these patients do not necessarily divulge their CAM use to their treating physicians and nurses. Although CAM use can be beneficial, some can be very harmful, especially for cancer patients. Association is known between camel products and brucellosis and Middle East respiratory syndrome coronavirus (MERS-CoV). Both can lead to tremendous morbidity in immune-compromised patients. Doctor-patient communication regarding CAM use is of paramount importance in cancer care.
\end{abstract}

Keywords: Complementary and alternative medicine, Religious belief, Cancer, Camel products, Brucellosis, Middle East respiratory syndrome coronavirus (MERS-CoV)

\footnotetext{
*Correspondence: ahmedkh1@ngha.med.sa; khadega444@yahoo.com

${ }^{1}$ King Abdullah International Medical Research Center, Riyadh, Saudi Arabia

2Department of Oncology, Ministry of National Guards, King Abdulaziz

Medical City, Riyadh, Saudi Arabia

Full list of author information is available at the end of the article
} 


\section{Background}

The National Center for Complementary and Integrative Health $(\mathrm{NCCIH})$ defines complementary medicine as a non-mainstream practice used together with conventional medicine and defines alternative medicine as a non-mainstream practice used in place of conventional medicine $[1,2]$. The use of CAM is widespread worldwide, ranging from $9.8 \%$ to $76 \%$, and the pattern of use differs according to socioeconomic status, geography, and religious and spiritual beliefs $[3,4]$. Among cancer patients, $10 \%$ to $80 \%$ reported CAM use, with prayer and nutritional supplements being the most common [5-9].

Patients with cancer may prefer CAM, which they might perceive as being "safe and natural" to chemotherapy and radiation therapy, which can alarm some patients. These patients do not necessarily understand that "natural" does not always mean "safe". Moreover, alternative practitioners can be perceived as caring, with a holistic interest in the patient's well-being, whereas oncologists tend to direct their discussions with their patients toward specific aspects of the disease [10, 11].

CAM use is widely practiced the in the Saudi community (33-93.3\%) [12-17]. The majority of CAM users in the Saudi community obtain their information about CAM from friends, families, and the media [10]. The majority of CAM used in Saudi Arabia (dietary and nondietary) are of a religious nature, such as supplication and recitation of the Quran, consumption of Zamzam water (water from holy Mecca), regularly drinking water upon which the Quran has been read, and cupping/ hijama. Drinking honey, camel milk, and camel urine, which are all mentioned in the Holy Quran as therapeutic measures, are also commonly used in Saudi Arabia [10]. The Ministry of Health $(\mathrm{MOH})$ provides free medical services for all Saudis, excluding traditional healers' and CAM costs. CAM practice is regulated by the National Complementary and Alternative Medicine Center established by the MOH [18].

Only two previous studies have explored CAM use among cancer patients in Saudi Arabia, and both showed very discrepant results $[16,17]$. It is unclear whether the differences in reported prevalence and CAM types are due to interregional differences or related to differences in the surveys used.

There has been a recent noticeable increase in the publicity of camel products in Saudi Arabia due to the common belief in the positive effects of them in different diseases. Camel products have been linked to brucellosis and Middle East respiratory syndrome coronavirus (MERS-CoV); however, Saudis continue to consume camel products. During the 2014 MERS-CoV outbreak, all cancer patients who encountered the infection in King Abdulaziz Medical City, Riyadh, died from the infection (a total of 15). We have also noticed increasing numbers of brucellosis infections in our cancer patients. In the previous two papers, the issue of camel products (milk and urine) was not fully addressed $[16,17]$

The aim of this study was to reevaluate CAM use among Saudi patients with cancer and to explore the patients' insights and beliefs about CAM use. We also sought to assess the willingness of patients with cancer to divulge their use of CAM to their nurses and physicians.

\section{Methods}

\section{Ethical approval}

Approval for this study was provided by the King Abdullah International Medical Research Center Institutional Review Board (RC 16/165/R). Written informed consent was given by all participants prior to participation in the study.

\section{Setting}

This cross-sectional, survey-based study was conducted in two oncology wards, with 24 beds in each, one used for patients with solid tumor and the other for patients with hematological malignancies and stem-cell transplantation, and in oncology outpatient clinics at the King Abdulaziz Medical City in Riyadh.

\section{Participant selection}

Adult patients with confirmed cancer diagnoses, specifically hematological malignancies and solid tumors, were approached in person between July 1 and December 31, 2016, and were asked about their willingness to participate after explaining the purpose of the study. Patients who were actively receiving and those who had completed cancer-directed therapy within the past year were asked to participate. Patients who were known to have mental disorders were excluded.

\section{Tool}

A previously developed questionnaire used by Jazieh AR et al. (2012), which was based in Jazieh AR et al. (2004), was modified to include patients with hematological malignancies and those undergoing hematopoietic stemcell transplantation (HSCT), translated into Arabic and translated back to English for consistency [17, 19]. The questionnaire was administered to 15 participants and was subsequently adjusted to overcome inconsistency and to ensure reliability.

The research coordinators collected demographic and disease profile data from medical records and used the validated questionnaire in a face-to-face interview with the participants (Additional file 1).

During the interview, participants were asked about specific practices and therapies they use for their cancer, 
other than what is prescribed by their treating doctors, including Quran recitation; supplication; or consumption of any dietary or non-dietary materials or supplements, including Zamzam water, water upon which the Quran has been read, black seeds (Nigella sativa), camel milk, camel urine, garlic, olive oil, multivitamins, known herbal remedies, and unknown herbal mixtures.

We allowed participants to mention any form of CAM not listed in the questionnaire and listed those as "others." The questionnaire also included items exploring participants' perception and beliefs about CAM and transparency with health care providers regarding CAM use.

\section{Statistical analysis}

Responses to all questions were reviewed to avoid missing data before the end of each participant's interview. Data were entered into a Microsoft Access database and peer reviewed for quality checking. Validity constraints were applied to the database to ensure accuracy and consistency. The data were then exported to IBM SPSS Statistics for Windows, version 22.0 (Armonk, NY, USA) for analysis.

Frequencies of nominal categorical variables were compared by the Chi-square test, and continuous variables were compared by $t$-tests. Inferential analysis was performed by applying univariate analysis to examine the association between CAM use and demographic and clinical characteristics. Predictors of CAM use were also investigated by multivariate logistic regression. $P$ values $<$ 0.05 were considered statistically significant.

\section{Results}

\section{Participant characteristics}

A total of 156 cancer patients participated in the study. About half of the participants were females $(85 ; 54.4 \%)$ with a median age of 50 years (range 18-84). Compared to our institution's tumor registry, the gender distribution of our participants was almost equal, whereas the median age was slightly different (57 years). The demographic and clinical characteristics are summarized in Table 1.

\section{Pattern of CAM use}

The prevalence of the use of CAM was $69.9 \%$, with a confidence interval of $62.02 \%$ to $76.95 \%$. The majority of CAM users $(71 \%)$ started using CAM after being diagnosed with cancer. Only $3.7 \%$ of participants indicated that they had delayed cancer treatment in favor of CAM use. The most common reported types of CAM were those of a religious nature, such as supplication, Quran recitation, Zamzam water, and water upon which Quran has been read. Among non-religious CAM, olive oil was
Table 1 Participants' characteristics $(n=156)$

\begin{tabular}{|c|c|c|c|}
\hline \multicolumn{2}{|l|}{ Characteristic } & \multirow{2}{*}{$\begin{array}{l}\text { Number } \\
71\end{array}$} & \multirow{2}{*}{$\frac{\text { Percent }}{45.5}$} \\
\hline Gender & Male & & \\
\hline & Female & 85 & 54.5 \\
\hline \multirow[t]{2}{*}{ Marital status } & Married & 123 & 78.8 \\
\hline & Single & 33 & 21.1 \\
\hline \multirow[t]{3}{*}{ Education level } & Uneducated & 37 & 23.7 \\
\hline & Higher education & 47 & 30.1 \\
\hline & Lower education & 72 & 46.1 \\
\hline \multirow[t]{3}{*}{ Work status } & Not working & 82 & 52.6 \\
\hline & Working & 38 & 24.4 \\
\hline & Retired & 36 & 23.1 \\
\hline \multirow[t]{3}{*}{ Monthly income } & $\leq$ SR 6000 & 59 & 37.8 \\
\hline & $>$ SR 6000 & 93 & 59.6 \\
\hline & Rather not state & 4 & 2.6 \\
\hline \multirow[t]{3}{*}{ Smoking } & Current & 17 & 10.9 \\
\hline & Former & 23 & 14.7 \\
\hline & Never smoked & 116 & 74.4 \\
\hline \multirow[t]{2}{*}{ Cancer type } & Solid tumor & 128 & 82.1 \\
\hline & Hematological malignancy & 28 & 17.9 \\
\hline \multirow[t]{3}{*}{ Cancer stage } & Non-metastatic & 94 & 60.3 \\
\hline & Metastatic & 34 & 21.8 \\
\hline & NA & 28 & 17.9 \\
\hline \multirow[t]{4}{*}{ Type of treatment } & Surgery & 90 & 57.7 \\
\hline & Radiation & 69 & 44.2 \\
\hline & Chemotherapy & 131 & 84 \\
\hline & Stem cell transplant & 16 & 10 \\
\hline
\end{tabular}

Higher education: college and postgraduate, lower education: elementary to high school, NA: not applicable, SR: Saudi riyals

the most commonly used, followed by black seeds (Nigella sativa) (Table 2).

There was a clear overlap between different types of CAM used. The majority of participants used dietary and religious-based CAM concurrently, whereas only $1.8 \%$ used only dietary CAM. Almost all camel urine users $(94.1 \%)$ also used camel milk; garlic users commonly used it with olive oil, with black seeds (Nigella sativa), or with both (Fig. 1).

A univariate analysis was conducted to investigate the effects of demographic and clinical factors on CAM use. We excluded Quran recitation and supplication from this univariate and multivariate association analysis, because their use was very common (supplication 95.4\%; Quran recitation 88.1\%). CAM was significantly associated with gender $(62.2 \%$ of CAM users were female, compared with $37.8 \%$ male, $p=0.011$ ), employment status $(57.1 \%$ of CAM users were unemployed, $26.5 \%$ employed, and $16.3 \%$ retired, $p=0.034$ ), and radiation 
Table 2 Frequency of use of different types of complementary and alternative medicine (CAM)

\begin{tabular}{llll}
\hline & & Number & Percent \\
\hline CAM use & Users & 109 & 69.9 \\
Types of CAM & Non-users & 47 & 30.1 \\
& Supplication & 103 & 94.5 \\
& Quran recitation & 96 & 88.1 \\
& Zamzam water & 92 & 84.4 \\
& Water read upon Quran & 69 & 63.3 \\
& Olive oil & 61 & 56.0 \\
& Black seed (Nigella sativa) & 40 & 37.0 \\
& Garlic & 36 & 33.3 \\
& Camel milk & 26 & 24.1 \\
& Honey & 24 & 22.0 \\
& Camel urine & 17 & 15.7 \\
& Known herbal remedies & 16 & 14.7 \\
& Multivitamins & 11 & 10.1 \\
Unknown herbal mixture & 4 & 3.7 \\
Others & & 6 & 5.5 \\
\hline
\end{tabular}

${ }^{a}$ Dates, turmeric, mushrooms, and yogurt

therapy (54.1\% of CAM users had received radiotherapy, $45.9 \%$ had not, $p=0.008$ ) (Table 3 ).

Multivariate logistic regression analysis confirmed a relationship with CAM use for both gender and radiation therapy $(\mathrm{OR}=3.375, p=0.029$; and $\mathrm{OR}=3.036, p=0.015$, respectively). In addition, the analysis showed that younger age and not having received surgery were also predictors of CAM use (Table 4).

\section{Participants' beliefs regarding CAM use}

Among cancer patients who used CAM, a variety of reasons were given for this decision: $75 \%$ reported that they were using CAM as a treatment for cancer. Other reported reasons were to improve mood (18.3\%), to control pain (11.9\%), to improve the immune system (11\%), to increase fitness (6.4\%), and to improve appetite (4.6\%). Although 28 (25.7\%) reported no improvement after CAM use, the remaining 81 (74.3\%) reported some overlapping improvement in terms of enhancement of mood (56.8\%), appetite (23.5\%), physical strength (7.4\%), and immunity (2.5\%) as well as reduction of pain (33.3\%). Among those who felt some improvement with CAM use, $77.8 \%$ attributed the improvement to both cancer treatment and CAM use, whereas $14.8 \%$ believed their improvement was related to medical therapy and only $7.4 \%$ thought that CAM use was the only reason for their perceived improvement.

Among the patients who did not use CAM, 40.4\% stated that CAM use did not cross their minds when

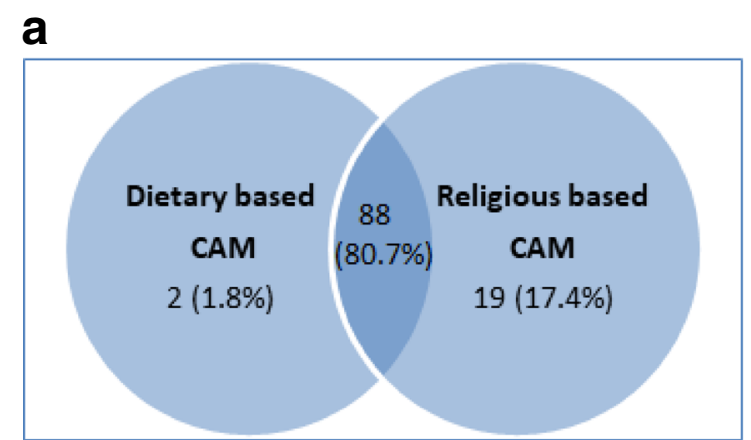

b

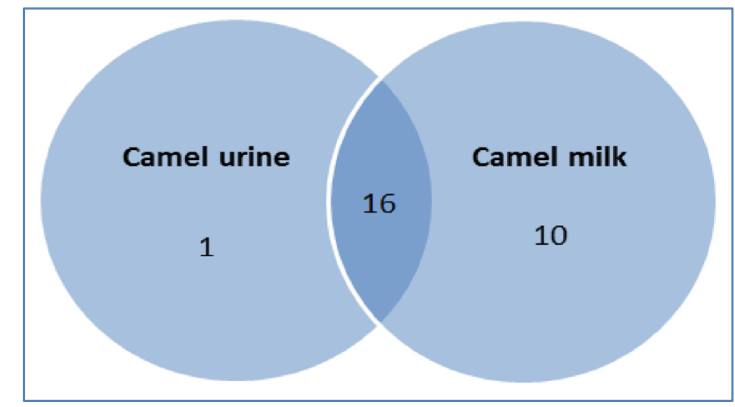

c

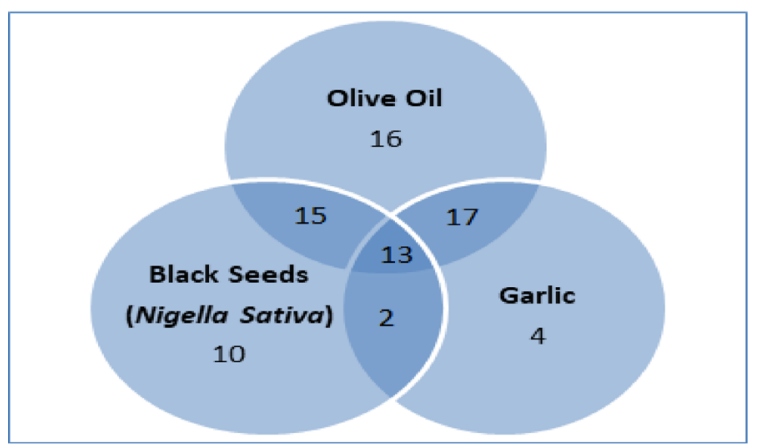

Fig. 1 Venn Diagrams demonstarting overlapping usage of different types of complementary and alternative medicine (CAM). Dietary vs.religious based CAM use (a); camel product users tend to use both (b); dietary based CAM overlap (c)

they were considering treatment options, $31.9 \%$ were advised by their doctor not to use CAM, 29.8\% did not think that CAM use was beneficial, $4.3 \%$ were not aware of CAM use for cancer, and only $2.1 \%$ mentioned cost as the main reason for not using CAM.

\section{Divulgence of CAM use to healthcare workers}

Whereas 19\% of CAM users reported that they had discussed the issue with their doctors, only $8 \%$ and $3 \%$ had done so with their educator or nurse, respectively. Among those who discussed their CAM use with their doctors, $42.9 \%$ perceived their doctor's response to be supportive, $33.3 \%$ unsupportive, and $23.8 \%$ neutral. Patient educator's responses were perceived as unsupportive in $44.4 \%$ of the 
Table 3 Univariate analysis of the association between complementary and alternative medicine (CAM) use and demographic and clinical factors

\begin{tabular}{|c|c|c|c|c|c|c|}
\hline & & \multicolumn{4}{|c|}{ CAM use } & \multirow{3}{*}{$p$} \\
\hline & & \multicolumn{2}{|l|}{$\overline{\mathrm{No}}$} & \multicolumn{2}{|l|}{ Yes } & \\
\hline & & $\bar{n}$ & $\%$ & $n$ & $\%$ & \\
\hline \multicolumn{2}{|l|}{ Age (years) median (range) } & \multicolumn{2}{|c|}{$55(18-84)$} & \multicolumn{2}{|c|}{$49(19-83)$} & 0.051 \\
\hline \multirow[t]{2}{*}{ Gender } & Male & 34 & 58.6 & 37 & 37.8 & $0.011^{\mathrm{a}}$ \\
\hline & Female & 24 & 41.4 & 61 & 62.2 & \\
\hline \multirow[t]{2}{*}{ Marital status } & Married & 44 & 75.9 & 79 & 80.6 & 0.483 \\
\hline & Unmarried & 14 & 24.1 & 19 & 19.4 & \\
\hline \multirow[t]{3}{*}{ Education level } & Higher education & 15 & 25.9 & 32 & 32.7 & 0.650 \\
\hline & Lower education & 29 & 50.0 & 43 & 43.9 & \\
\hline & Uneducated & 14 & 24.1 & 23 & 23.5 & \\
\hline \multirow[t]{3}{*}{ Work status } & Not working & 26 & 44.8 & 56 & 57.1 & $0.034^{a}$ \\
\hline & Working & 12 & 20.7 & 26 & 26.5 & \\
\hline & Retired & 20 & 34.5 & 16 & 16.3 & \\
\hline \multirow[t]{2}{*}{ Monthly income } & $\leq$ SR 6000 & 21 & 37.5 & 38 & 39.6 & 0.799 \\
\hline & $>$ SR 6000 & 35 & 62.5 & 58 & 60.4 & \\
\hline \multirow[t]{2}{*}{ Cancer type } & Solid tumor & 46 & 79.3 & 82 & 83.7 & 0.493 \\
\hline & Hematological malignancy & 12 & 20.7 & 16 & 16.3 & \\
\hline \multirow[t]{2}{*}{ Solid tumor stage } & Non-metastatic & 36 & 78.3 & 58 & 70.7 & 0.355 \\
\hline & Metastatic & 10 & 21.7 & 24 & 29.3 & \\
\hline \multirow[t]{2}{*}{ Surgery } & No & 23 & 39.7 & 43 & 43.9 & 0.606 \\
\hline & Yes & 35 & 60.3 & 55 & 56.1 & \\
\hline \multirow[t]{2}{*}{ Radiation } & No & 42 & 72.4 & 45 & 45.9 & $0.001^{a}$ \\
\hline & Yes & 16 & 27.6 & 53 & 54.1 & \\
\hline \multirow[t]{2}{*}{ Chemotherapy } & No & 12 & 20.7 & 13 & 13.3 & 0.222 \\
\hline & Yes & 46 & 79.3 & 85 & 86.7 & \\
\hline
\end{tabular}

SR: Saudi riyals

${ }^{\text {a }}$ The Chi-square statistic is significant at $<0.05$

Higher education: college and postgraduate, Lower education: elementary to high school

Table 4 Multivariate logistic regression analysis of between complementary and alternative medicine (CAM) use and demographic and clinical factors

\begin{tabular}{|c|c|c|c|c|c|}
\hline & & \multirow[b]{2}{*}{$p$} & \multirow[b]{2}{*}{ OR } & \multicolumn{2}{|c|}{$95 \%$ C.I. for OR } \\
\hline & & & & Lower & Upper \\
\hline Age & & $0.032^{*}$ & 0.960 & 0.926 & 0.996 \\
\hline Gender & Female vs. male & $0.029^{*}$ & 3.375 & 1.129 & 10.087 \\
\hline Marital status & Married vs. unmarried & 0.175 & 2.119 & 0.716 & 6.269 \\
\hline \multirow[t]{2}{*}{ Education } & Higher education vs. uneducated & 0.856 & 1.143 & 0.271 & 4.818 \\
\hline & Lower education vs. uneducated & 0.448 & 0.634 & 0.196 & 2.055 \\
\hline Work status & Unemployed vs. employed & 0.583 & 1.380 & 0.438 & 4.347 \\
\hline Monthly income & $\leq$ SR 6000 vs. $>$ SR 6000 & 0.242 & 1.822 & 0.667 & 4.981 \\
\hline Cancer stage & Non-metastatic vs. metastatic & 0.979 & 0.987 & 0.359 & 2.710 \\
\hline Surgery & Yes vs. no & $0.030^{*}$ & 0.318 & 0.113 & 0.896 \\
\hline Radiation & Yes vs. no & $0.015^{*}$ & 3.036 & 1.237 & 7.451 \\
\hline Smoking status & Current or former vs. never smoked & 0.254 & 2.133 & 0.580 & 7.853 \\
\hline
\end{tabular}

*The $p$ value is significant at $<0.05$ 
cases, supportive in $33.3 \%$, and neutral in $22.2 \%$.The nurses' responses were perceived to be equally distributed among supportive, unsupportive, and neutral.

\section{Discussion}

Interest in CAM is growing worldwide, especially in the era of the Internet and social networking, which is rich in reports by patients of their positive personal experiences of CAM [20, 21]. Despite tremendous progress in cancer therapy [20], a significant proportion of patients with cancer use CAM along with their medical therapies $[9,21]$. Although $71 \%$ of CAM users started their CAM use after cancer diagnosis, the remaining $29 \%$ reported starting CAM use prior to their cancer diagnosis, which concurs with the previously reported high rate of CAM use in the Saudi general population [12].

Previous studies exploring CAM use among Saudi cancer patients are limited and of small sample sizes. However, they showed variable results; Sait et al. showed a prevalence of only $20 \%$, whereas Jazieh et al. suggested that CAM use is highly prevalent (reaching 90\%) $[16,17]$. In our study, the prevalence of CAM use was $69.9 \%$, and the most prominent types of CAM were those of a religious nature. The great degree of variability between the two studies is similar to the variability in CAM use reported by different studies in the Saudi community and could be explained by the studies' distinct methodologies and the fact that the majority of those studies were conducted in single institutions [12].

CAM has some beneficial outcomes in cancer patients, such as pain relief, nausea control, mood enhancement, and control of fatigue [22-24]. However, there are potential risks when cancer patients use some types of CAM, especially when they are actively receiving conventional therapies for their cancer. Some dietary herbs can lead to severe hepatotoxicity necessitating liver transplantation and even death $[25,26]$. Liver damage related to hepatotoxic herbs can be further augmented with some conventional cancer therapies and vice versa, and some herbal remedies, such as gingko, kava, ginseng, and garlic, may interfere with liver metabolism of anticancer drugs, leading to either decreasing cancer drug therapeutic effect or augmenting toxicities [27].

Brucellosis is very common in the Middle East region, and it has been directly linked to contact with camel urine and consumption of unheated camel milk [28-33]. The fatal Middle East respiratory syndrome coronavirus (MERS-CoV) has been linked to contact with camels and consumption of raw camel milk [34, 35]. Although we did not ask in this study whether the milk was heated prior to consumption, it is a known custom in Saudi Arabia to drink camel milk raw. Among CAM users in this study, $94.1 \%$ of those who drink camel urine also use camel milk. In the Middle East region, it is paramount for health care workers, especially those caring for cancer patients, to discuss with their patients the potential risks of using camel products.

Previous studies exploring CAM use among Saudi cancer patients were conducted prior to the outbreak of MERS-Co. Sait et al. did not explore other important CAM such as camel products, whereas Jazieh et al. reported an $8.6 \%$ rate of camel urine use and $9.3 \%$ milk use without mentioning the milk source $[16,17]$.

Evidence suggests that a considerable number of CAM users do not discuss this practice with their healthcare providers [16]. In our study, only one-third of CAM users divulged their CAM use to their treating physicians, and fewer patients informed their educators and nurses. Healthcare workers might not discuss CAM use with their patients because they are either busy or are not well-informed about CAM. In addition, patients with cancer and their families likely expect that most healthcare workers, including oncologists, do not support the use of CAM despite its widespread acceptance in the general community. It is important for CAM use to be routinely explored with all patients with cancer who are undergoing active conventional therapy, given the compromised immune status of such patients, the possible interaction with conventional cancer therapy, and the potential CAM-related liver toxicity.

Although some health care workers might be completely against CAM, it is evident that CAM use is beneficial in many aspects of cancer patients' lives [24] .In this study, three-quarters of our CAM users (74.3\%) felt some improvement in different aspects such as mood (56.8\%), appetite (23.5\%), physical strength $(7.4 \%)$, and immunity (2.5\%) as well as reduction of pain after CAM use. Among those who felt some improvement, $7.4 \%$ thought that CAM use was the only reason for their perceived improvement, whereas $77.8 \%$ attributed the improvement to both conventional cancer therapies and CAM use, and $14.8 \%$ believed their improvement was related to conventional cancer therapy.

Only small numbers of patients with cancer adopt CAM treatments in lieu of mainstream therapy [12]. In our study, only $3.7 \%$ of CAM users delayed conventional cancer-directed therapy. However, we interviewed patients who attended oncology clinics or who were admitted to the oncology floor, and these patients were likely to have received conventional therapies for their cancers. A large, community-based study should provide a better estimate of the number of patients who adopt CAM instead of conventional therapy.

Our study has some limitations: first, the small sample size in a single institution may not be representative of the Saudi community; second, recruiting patients attending a cancer center will miss cancer patients who elect to use CAM only without seeking medical advice. 


\section{Conclusions}

The use of CAM is highly prevalent among cancer patients in the Middle East and includes camel products, but these patients do not necessarily divulge their CAM use to their treating physicians and nurses. Although CAM use can be beneficial, some can be very harmful, especially to cancer patients. Association between camel products and brucellosis and MERS-CoV is well-known. Both can lead to tremendous morbidity in immunecompromised patients; therefore, doctor-patient communication regarding CAM use is paramount in cancer care.

\section{Additional file}

Additional file 1: A previously developed questionnaire used by Jazieh AR et al. (2012), which was based in Jazieh AR et al. (2004), was modified to include patients with hematological malignancies and those undergoing hematopoietic stem-cell transplantation (HSCT), translated into Arabic and translated back to English for consistency. (DOCX 42 kb)

\section{Abbreviations}

CAM: Complementary and alternative medicine; CT: Conventional therapies; HSCT: Hematopoietic stem-cell transplantation; MERS-CoV: Middle East respiratory syndrome coronavirus

\section{Acknowledgments}

Not applicable

\section{Funding}

This study did not require any funding.

\section{Availability of data and materials}

The data sets used and/or analyzed during the current study are available from the corresponding author on reasonable request.

\section{Authors' contributions}

KAA participated in the conception and design of the study and wrote the manuscript; YA, TA, and AA collected data and edited the manuscript; YZA analyzed and interpreted the data and critically revised the article; ARJ participated in the conception and design of the study and critically revised the article. All authors read and approved the final manuscript.

\section{Ethics approval and consent to participate}

Approval for this study was provided by the King Abdullah International Medical Research Center Institutional Review Board (RC 16/165/R). Written informed consent was given by all participants prior to participation in the study.

\section{Consent for publication}

Not applicable

\section{Competing interests}

The authors declare that they have no competing interests.

\section{Publisher's Note}

Springer Nature remains neutral with regard to jurisdictional claims in published maps and institutional affiliations.

\section{Author details}

'King Abdullah International Medical Research Center, Riyadh, Saudi Arabia. 2Department of Oncology, Ministry of National Guards, King Abdulaziz Medical City, Riyadh, Saudi Arabia. ${ }^{3}$ King Saud bin Abdulaziz University for Health Sciences, Riyadh, Saudi Arabia.
Received: 15 June 2017 Accepted: 1 March 2018

Published online: 12 March 2018

\section{References}

1. National Center for Complementary and Integrative Health. Alternative or Integrative: What's in a name?.https://nccih.nih.gov/health/integrativehealth\#cvsa. Last accessed 29 Oct 2017.

2. The Use of Complementary and Alternative Medicine in the United States: About CAM. https://nccih.nih.gov/research/statistics/2007/camsurvey_fs1. htm. Last accessed 29 Oct 2017.

3. Harris PE, Cooper KL, Relton C, Thomas KJ. Prevalence of complementary and alternative medicine (CAM) use by general population a systematic review and update. Int J Clin Pract. 2012;66:924-39.

4. Posadzki P, Watson LK, Alotaibi A, Ernst E. Prevalence of use of complementary and alternative medicine (CAM) by patients/consumers in the UK: systematic review of surveys. Clin Med (Lond). 2013;13:126-31.

5. Paul M, Davey B, Senf B, Stoll C, Munstedt K, Mucke R, et al. Patients with advanced cancer and their usage of complementary and alternative medicine. J Cancer Res Clin Oncol. 2013;139:1515-22.

6. Lee MM, Chang JS, Jacobs B, Wrensch MR. Complementary and alternative medicine use among men with prostate cancer in 4 ethnic populations. Am I Public Health. 2002:92:1606-9.

7. Chrystal K, Allan S, Forgeson G, Isaacs R. The use of complementary/alternative medicine by cancer patients in a New Zealand regional cancer treatment Centre. NZ Med J. 2003;116:U296.

8. Cassileth BR, Deng G. Complementary and alternative therapies for cancer. Oncologist. 2004;9:80-9.

9. Shukla Y, Pal SK. Complementary and alternative cancer therapies: past, present and the future scenario. Asian Pac J Cancer Prev. 2004;5:3-14.

10. Adams M, Jewell AP. The use of complementary and alternative medicine by cancer patients. Int Semin Surg Oncol. 2007;4:10 Verhoef MJ, Balneavea LG, boon HS, Vroegindewey a. Reasons for and characteristics associated with complementary and alternative medicine use among adult cancer patients: a systematic review. Integr Cancer Ther. 2005;4:274-86.

11. White MA, Verhoef MJ, Davison BJ, Gunn H, Cooke K. Seeking mind, body and Spirit healing-why some men with prostate cancer choose CAM (complementary and alternative medicine) over conventional cancer treatments. Integr Med Insights. 2008;3:1-11.

12. Alrowais NA, Alyousefi NA. The prevalence extent of complementary and alternative medicine (CAM) use among Saudis. Saudi Pharm J. 2017;25:306-18.

13. Al-Faris EA. The pattern of alternative medicine use among patients attending health centers in a military community in Riyadh. J Family Community Med. 2000;7:17-25.

14. AlBedahAM KMK, Alolemy AT, Al Mudaiheem AA, Al Eidi S, Al-Yahia OA, et al. The use and out-of-pocket spending on complementary and alternative medicine in Qassim province, Saudi Arabia. Ann Saudi Med. 2013;33:282-9.

15. Al-Saeedi M, Elzubier AG, Bahnassi AA, Al-Dawood KM. Patterns of belief and use of traditional remedies by diabetic patients in mecca. Saudi Arabia East Mediterr Health J. 2003;9:99-107.

16. Sait KH, Anfinan NM, Eldeek B, Al-Ahmadi J, Al-Attas M, Sait HK, et al. Perception of patients with cancer towards support management services and use of complementary alternative medicine.. A single institution hospital-based study in Saudi Arabia. Asian Pac J Cancer Prev. 2014;15:2547-54.

17. Jazieh AR, Al Sudairy R, Abulkhair O, Alaskar A, Al Safi F, Sheblaq N, et al Use of complementary and alternative medicine by patients with cancer in Saudi Arabia. J Altern Complement Med. 2012;18:1045-9.

18. AlBedah A. Challenges and future plan for national center of complementary medicine center in Saudi Arabia. (Tabt) Arab. Periodical J Nat Center Complement Med Center Saudi Arabia. 2012;1:5

19. Jazieh AR, Kopp M, Foraida M, Ghouse M, Khalil M, Savidge M, et al. The use of dietary supplements by veterans with cancer. J Altern Complement Med. 2004;10:560-4.

20. Ventola $\mathrm{CL}$. Current issues regarding complementary and alternative medicine (CAM) in the United States. Part 3: policies and practices regarding dietary supplements in health care facilities. PT. 2010;35:570-6.

21. Clarke TC, Black LI. Trends in the use of complementary health approaches among adults: United States, 2002-2012. Natl Health Stat Report. 2015;10:1-16.

22. Burstein HJ, Krilov L, Aragon-Ching JB, Baxter NN, Chiorean EG, Chow WA, et al. Clinical cancer advances 2017: annual report on progress against cancer from the American Society of Clinical Oncology. J ClinOncol. 2017;35:1341-67. 
23. Wojtacki J, Pawlowski L, Pawlowska I, Lichodziejewska-Niemeirko SM. Complementary and alternative medicine (CAM) use among patients with cancer undergoing palliative care: a pilot study of a single institution in Poland. J Clin Oncol. 2017;35(5_suppl):178.

24. Hoffman C. Benefits of complementary therapies. Breast Cancer Res. 2007; 9(Suppl 2):S9.

25. Navarro VJ, Barnhart H, Bonkovsky HL, Davern T, Fontana RJ, Grant L, et al. Liver injury from herbals and dietary supplements in the U.S. drug-induced liver injury network. Hepatology. 2014;60:1399-408.

26. Teo DC, Ng PS, Tan SH, Lim AT, Toh DS, Chan SY, Cheong HH. Drug-induced liver injury associated with complementary and alternative medicine: a review of adverse event reports in an Asian community from 2009 to 2014. BMC Complement Altern Med. 2016;16:192.

27. Sparreboom A, Cox MC, Acharya MR, Figg WD. Herbal remedies in the United States: potential adverse interactions with anticancer agents. J Clin Oncol. 2004;22:2489-503.

28. Hegazy AA, El-Dughaym A, Alknah M, Housawi FMT, Hatem ME. Studies on mastitis in female camels with special reference to brucellosis. J Camel Sci. 2004;1:96-102.

29. Abbas B, Agab H. A review of camel brucellosis. Prev Vet Med. 2002;55:47-56.

30. Omer MM, Musa MT, Bakheit MR, Perrett L. Brucellosis in camels, cattle and humans: association and evaluation of serological tests used for diagnosis of the disease in certain nomadic localities in Sudan. Rev Sci Tech. 2010;29:663-9.

31. Madkour MM. Brucillosis Butterworths. London. 1989;294

32. Kiel FW, Khan MY. Analysis of 506 consecutive positive serological tests for brucellosis in Saudi Arabia. J Clin Microbial. 1987;25:1384-7.

33. http://www.CDC.gov/brucellosis/index.html. Last accessed 29 Oct 2017.

34. Sikkema RS, Faraq EABA, Himatt S, Ibrahim AK, Al-Romaihi H, Al-Marri SA, et al. Identification of risk factors for primary Middle East respiratory syndrome corona virus infection in camel workers in Qatar during 2013-2014: a case-control study. J Infect Dis. 2017;215:1702-5.

35. Reusken CB, Farag EA, Jonges M, Godeke GJ, El-Sayed AM, Pas SD, et al. Middle East respiratory syndrome coronavirus (MERS-CoV) RNA and neutralizing antibodies in milk collected according to local customs from dromedary camels, Qatar, April 2014. Euro Surveill. 2014;19:20829.

\section{Submit your next manuscript to BioMed Central and we will help you at every step:}

- We accept pre-submission inquiries

- Our selector tool helps you to find the most relevant journal

- We provide round the clock customer support

- Convenient online submission

- Thorough peer review

- Inclusion in PubMed and all major indexing services

- Maximum visibility for your research

Submit your manuscript at www.biomedcentral.com/submit

) Biomed Central 